\title{
High-speed solar-blind photodetectors with indium-tin-oxide Schottky contacts
}

Necmi Biyikli, Ibrahim Kimukin, Tolga Kartaloglu, Orhan Aytur, and Ekmel Ozbay

Citation: Appl. Phys. Lett. 82, 2344 (2003); doi: 10.1063/1.1566459

View online: http://dx.doi.org/10.1063/1.1566459

View Table of Contents: http://aip.scitation.org/toc/apl/82/14

Published by the American Institute of Physics

\section{Articles you may be interested in}

High-speed visible-blind GaN-based indium-tin-oxide Schottky photodiodes

Applied Physics Letters 79, 2838 (2001); 10.1063/1.1412592

High gain ultraviolet photodetectors based on AIGaN/GaN heterostructures for optical switching Applied Physics Letters 98, 211114 (2011); 10.1063/1.3595303

High quantum efficiency AIGaN solar-blind p-i-n photodiodes Applied Physics Letters 84, 1248 (2004); 10.1063/1.1650550

Solar-blind AIGaN-based Schottky photodiodes with low noise and high detectivity Applied Physics Letters 81, 3272 (2002); 10.1063/1.1516856

Schottky barrier photodetector based on Mg-doped p-type GaN films Applied Physics Letters 63, 2455 (1998); 10.1063/1.110473

High-speed, low-noise metal-semiconductor-metal ultraviolet photodetectors based on GaN Applied Physics Letters 74, 762 (1999); 10.1063/1.123303

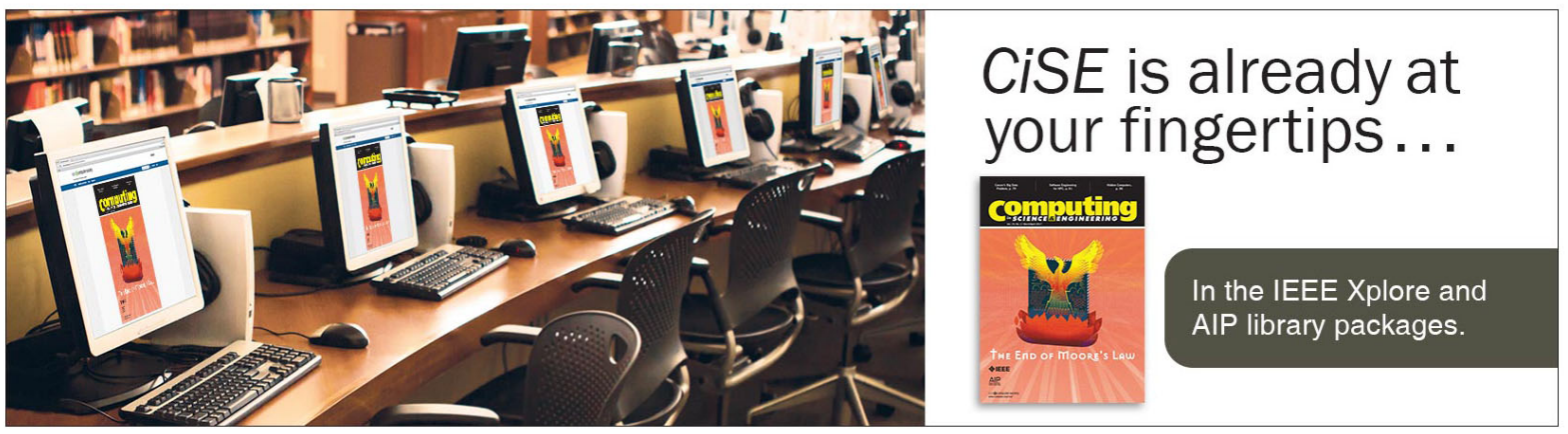




\title{
High-speed solar-blind photodetectors with indium-tin-oxide Schottky contacts
}

\author{
Necmi Biyiklia) \\ Department of Electrical and Electronics Engineering, Bilkent University, Bilkent Ankara 06533, Turkey \\ Ibrahim Kimukin \\ Department of Physics, Bilkent University, Bilkent Ankara 06533, Turkey \\ Tolga Kartaloglu and Orhan Aytur \\ Department of Electrical and Electronics Engineering, Bilkent University, Bilkent Ankara 06533, Turkey \\ Ekmel Ozbay \\ Department of Physics, Bilkent University, Bilkent Ankara 06533, Turkey
}

(Received 2 December 2002; accepted 12 February 2003)

\begin{abstract}
We report AlGaN/GaN-based high-speed solar-blind photodetectors with indium-tin-oxide Schottky contacts. Current-voltage, spectral responsivity, and high-frequency response characterizations were performed on the fabricated Schottky photodiodes. Low dark currents of $<1 \mathrm{pA}$ at $20 \mathrm{~V}$ reverse bias and breakdown voltages larger than $40 \mathrm{~V}$ were obtained. A maximum responsivity of $44 \mathrm{~mA} / \mathrm{W}$ at $263 \mathrm{~nm}$ was measured, corresponding to an external quantum efficiency of $21 \%$. True solar-blind detection was ensured with a cutoff wavelength of $274 \mathrm{~nm}$. Time-based high-frequency measurements at $267 \mathrm{~nm}$ resulted in pulse responses with rise times and pulse-widths as short as 13 and $190 \mathrm{ps}$, respectively. The corresponding 3-dB bandwidth was calculated as $1.10 \mathrm{GHz}$. (C) 2003 American Institute of Physics. [DOI: 10.1063/1.1566459]
\end{abstract}

Military and civil applications, such as missile warning and tracking systems, engine control, flame detection, chemical/biological agent sensing, and ozone-hole monitoring systems need high-performance photodetectors operating in the solar-blind spectrum $(\lambda<280 \mathrm{~nm}) .{ }^{1}$ Good detector performances reported for AlGaN-based solar-blind photodetectors proved their potential for replacing the photomultiplier tube and silicon-based detector technology. Solar-blind detectors with high responsivity, ${ }^{2,3}$ low dark current, ${ }^{4,5}$ high solar rejection, ${ }^{6,7}$ and high bandwidth ${ }^{8}$ were demonstrated using different detector designs based on AlGaN/GaN material system. Very recently Collins et al. have reported detectivity values comparable to the PMT detectivity performance with AlGaN $p-i-n$ photodiode (PD) structures. ${ }^{9,10}$

In terms of high-speed performance, GaN-based visibleblind photodiodes with $3-\mathrm{dB}$ bandwidths in the gigahertz regime were reported. ${ }^{11-13}$ However, the high-frequency measurements of AlGaN-based solar-blind PDs have resulted in lower bandwidths, with $100 \mathrm{MHz}$ as the best result. ${ }^{8,14-16}$ Previously, we had demonstrated low-noise solar-blind PDs with Au Schottky contacts. ${ }^{17}$ In this work, we present solarblind AlGaN Schottky PDs using indium-tin-oxide (ITO) Schottky contacts with high-speed performance at the gigahertz level. A comparative performance analysis has been made between ITO and Au Schottky PDs fabricated on the same wafer throughout the letter.

The epitaxial structure of the Schottky PD wafer was formed by $n-/ n+\mathrm{AlGaN} / \mathrm{GaN}$ heterostructure layers. A 0.8 - $\mu$ m-thick, undoped $\mathrm{Al}_{0.38} \mathrm{Ga}_{0.62} \mathrm{~N}$ layer was used as the absorption layer. The details of the epitaxial design can be found elsewhere. ${ }^{17}$ The fabrication process of the solar-blind

${ }^{a)}$ Electronic mail: biyikli@ee.bilkent.edu.tr
Schottky PDs was completed in five steps. Each step consisted of a photolithography followed by standard semiconductor fabrication processes, including metallization, lift-off, dry etch, and dielectric deposition. Fabrication started with the formation of $n+$ ohmic contacts. Before the deposition of $\mathrm{Ti} / \mathrm{Al}$ contact metal, the ohmic contact regions were etched down to the $n+$ ohmic layer using reactive ion etching. The metal was lifted off in acetone solution, and the samples were then annealed at $700^{\circ} \mathrm{C}$ for $30 \mathrm{~s}$. As the ohmic contacts were formed, the device mesas were defined using the same dry etch technique. ITO Schottky contacts were then deposited in an rf magnetron sputtering system. ${ }^{18}$ ITO films about $60 \mathrm{~nm}$ thick were grown with a deposition rate of $2 \AA / s$. The ITO films were etched to define the contact regions using dilute $\mathrm{HF}: \mathrm{H}_{2} \mathrm{O}$ solution. As the fourth step, a $\sim 120$-nm-thick $\mathrm{Si}_{3} \mathrm{~N}_{4}$ layer was deposited using plasma enhanced chemical vapor deposition. This nitride layer passivated the sample surface and protected the Schottky contacts. The fabrication was completed with the deposition and liftoff of Ti/Au interconnect metal pads.

Current-voltage measurements showed that ITO Schottky photodiodes exhibited low dark currents and high breakdown voltages. The solar-blind detectors exhibited dark-current density below $10 \mathrm{nA} / \mathrm{cm}^{2}$ at $20 \mathrm{~V}$ reverse bias. The breakdown voltages were higher than $40 \mathrm{~V}$. Figure 1 shows the measured $I-V$ curve of a $100 \times 100-\mu \mathrm{m}^{2}$ device. The dark-current level was lower for Au Schottky devices fabricated on the same wafer $\left(<1.8 \mathrm{nA} / \mathrm{cm}^{2}\right.$ at $\left.25 \mathrm{~V}\right){ }^{17}$ Turn-on voltages higher than $10 \mathrm{~V}$ were observed for ITO Schottky detectors, whereas Au Schottky devices showed turn-on about $2 \mathrm{~V}$.

Spectral responsivity of the detectors were measured in the 250-350-nm region. The output of a xenon lamp light 


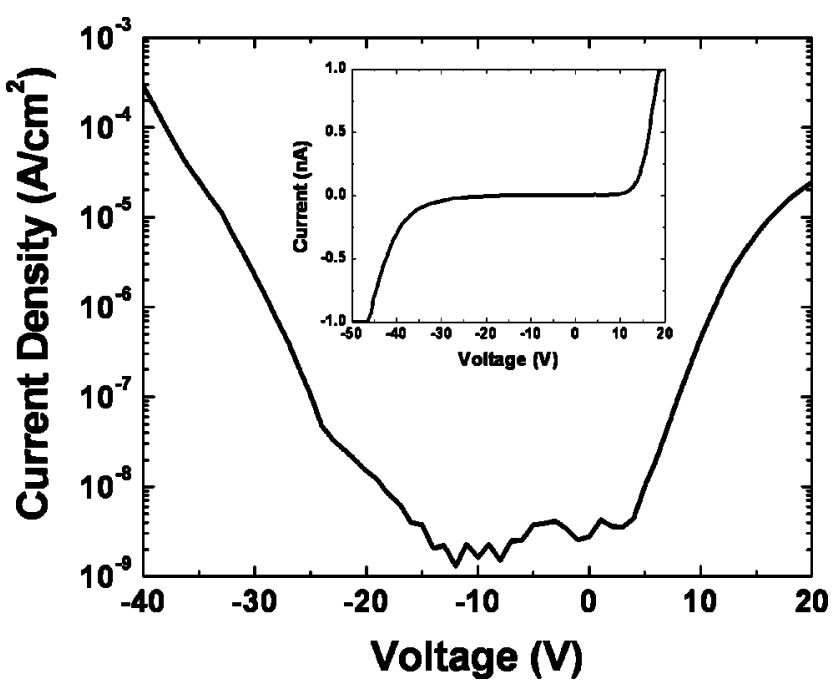

FIG. 1. Dark current density of a $100 \times 100-\mu \mathrm{m}^{2}$ solar-blind ITO Schottky $\mathrm{PD}$, as a function of reverse-bias voltage. The inset shows the $I-V$ curve of another $100 \times 100-\mu \mathrm{m}^{2}$ device in linear scale.

source was coupled into a single-pass monochromator. The output of the monochromator was fed into a multimode UV fiber by which the samples were illuminated. A calibrated $\mathrm{Si}$ photodetector was used to calibrate the optical power at the end of the fiber. The photocurrent generated by the detector was measured using a lock-in amplifier. The measured spectral responsivity of the ITO Schottky PD as a function of applied reverse bias voltage is shown in Fig. 2. A maximum device responsivity of $44 \mathrm{~mA} / \mathrm{W}$ at $263 \mathrm{~nm}$ was recorded under $50 \mathrm{~V}$ reverse bias. This corresponds to a peak external quantum efficiency of $21 \%$. The responsivity and efficiency values achieved with Au Schottky contacts were $89 \mathrm{~mA} / \mathrm{W}$ and $42 \%$ at $267 \mathrm{~nm}$, respectively. ${ }^{17}$ Increased optical absorption of the ITO film was responsible for the lower photoresponse of ITO Schottky detectors. Previous transmission/ reflection measurements had showed that ITO was more absorptive than $\mathrm{Au}$ for wavelengths smaller than $300 \mathrm{~nm} .{ }^{13}$ Although not as low as Au, the measured resistivity of ITO film $\left(2 \times 10^{-4} \Omega \mathrm{cm}\right)$ was low enough to ensure good elec-

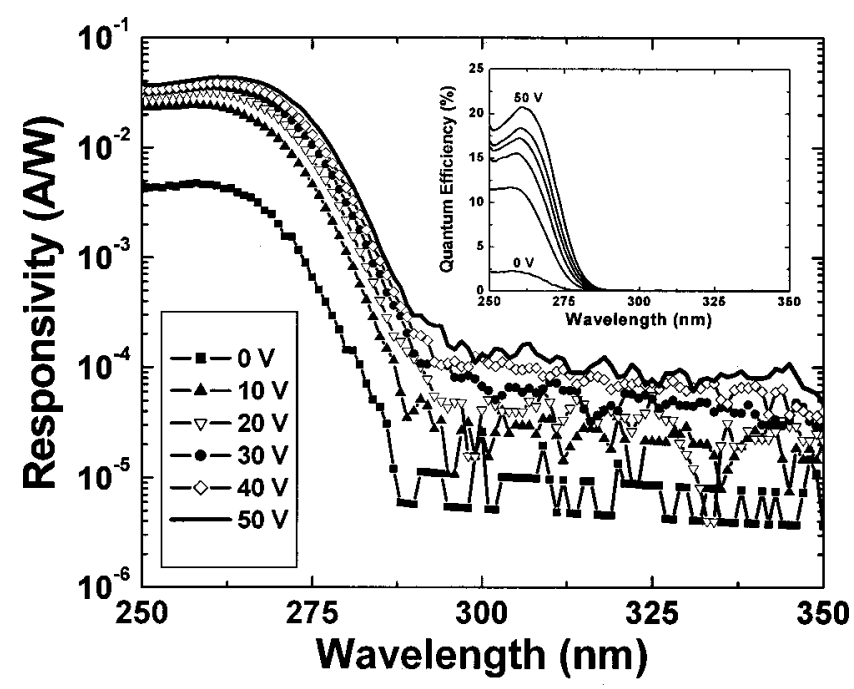

FIG. 2. Reverse-bias-dependent spectral photoresponses of AlGaN ITO Schottky PDs, measured at room temperature. In the inset, the corresponding external quantum efficiency curves are plotted.
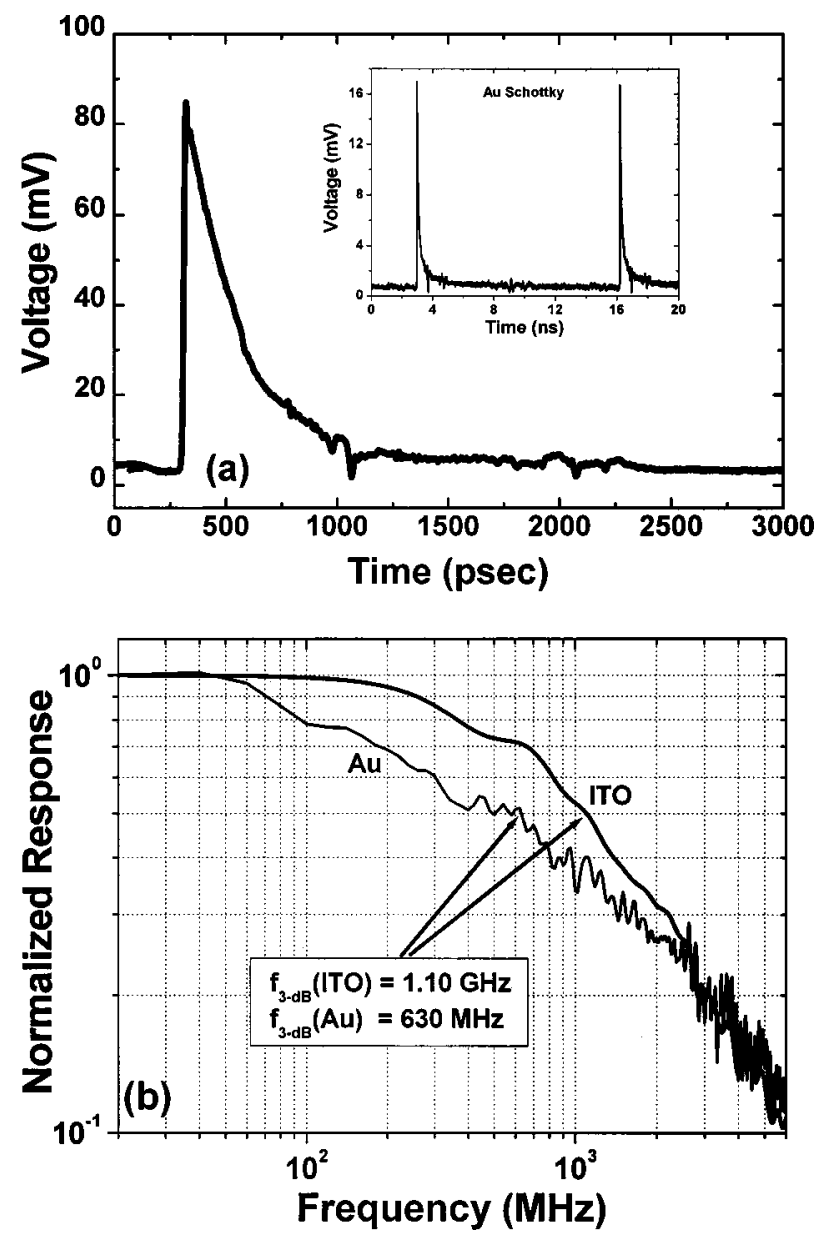

FIG. 3. (a) Temporal pulse response of a $60-\mu$ m-diameter AlGaN ITO Schottky photodiode taken at $-13-\mathrm{V}$ bias. Inset shows the pulse response of a 30- $\mu$ m-diameter Au Schottky device under $-15-\mathrm{V}$ bias. (b) Calculated FFT curves of the temporal data.

trical performance without effecting the photoresponse of the devices. The inset figure shows the corresponding external quantum efficiency curves of solar-blind ITO Schottky photodetectors. Like Au Schottky devices, ITO Schottky detectors displayed a true solar-blind characteristic with a cut-off wavelength of $274 \mathrm{~nm}$. At $350 \mathrm{~nm}$, the device responsivity has dropped by over three orders of magnitude from its peak value. This solar-blind/near-UV rejection exceeded four orders of magnitude for Au Schottky devices.

We have characterized the high-frequency response of solar-blind Schottky detectors at $267 \mathrm{~nm}$. To produce fast pulses at this wavelength, a laser setup with two nonlinear crystals were used. ${ }^{19}$ A Coherent Mira 900F model femtosecond mode-locked Ti:sapphire laser was used to generate the pump beam at $800 \mathrm{~nm}$. The pump pulses were produced with $76-\mathrm{MHz}$ repetition rate and $140-\mathrm{fs}$ pulse duration. These pulses were frequency doubled to generate a secondharmonic beam at $400 \mathrm{~nm}$ using a 0.5 -mm-thick type-I $\beta$-BaB2O4 (BBO) crystal. The second-harmonic beam and the remaining part of the pump beam were frequency summed to generate a third-harmonic output beam at $267 \mathrm{~nm}$ using another type-I BBO crystal with thickness of $0.3 \mathrm{~mm}$. The resulting 267-nm pulses had pulsewidths below $1 \mathrm{ps}$ and were focused onto the devices using UV-enhanced mirrors and lenses. The detectors were biased on a microwave probe 
station using a dc voltage source and a $40-\mathrm{GHz}$ bias-tee. Temporal pulse responses of the devices were observed on a 50-GHz sampling oscilloscope.

Pulse responses of devices with different device areas were measured. Faster pulse responses were obtained with smaller detectors due to smaller RC time constants. The pulse width decreased from $1.46 \mathrm{~ns}$ to $190 \mathrm{ps}$ as the diameter of the device area changed from 200 to $60 \mu \mathrm{m}$. The pulse response of a $60-\mu \mathrm{m}$-diameter ITO Schottky detector under $13 \mathrm{~V}$ reverse bias is shown in Fig. 3(a). The detector response exhibited a very short rise time of 13 ps and a rather long decaying fall time. The full-width at half-maximum (FWHM) was measured as 190 ps. The inset figure shows the pulse response taken under $15 \mathrm{~V}$ reverse bias of a 30$\mu$ m-diameter Au Schottky detector with 13-ps rise time and 74-ps FWHM. Figure 3(b) shows the corresponding fast Fourier transforms (FFTs) of the pulse responses achieved with ITO and Au Schottky detectors. The 3-dB bandwidth of ITO Schottky detector was calculated as $1.10 \mathrm{GHz}$. With this result, over an order of magnitude improvement in highspeed performance was achieved for solar-blind photodetectors. Despite having a shorter FWHM, the 3-dB bandwidth of Au Schottky device was lower (630 MHz) due to the longer fall time component. To understand the relaxation mechanism of these devices, exponential fitting have been made to the measured pulse responses. A good first-order fit with a time constant of $\sim 260$ ps was obtained for ITO Schottky PD, whereas the calculated RC time constant was around 15 ps. However, to fit the Au Schottky device response, a second-order exponential fit was needed. These results show that mechanisms other than $\mathrm{RC}$ and transit time limitations were responsible for the decay part of the highspeed response of these solar-blind detectors. We postulate that the long and multiexponential decay times are related to the carrier-trapping effect in AlGaN and carrier diffusion component originating from low field regions close to the center of the mesa. A detailed study on relaxation mechanisms of solar-blind AlGaN PDs is planned.

In conclusion, we have reported high-speed solar-blind photodiodes with ITO Schottky contacts on AlGaN/GaN heterostructures. The Schottky detectors exhibited low dark current $(<1 \mathrm{pA}$ at $20 \mathrm{~V})$ and a peak responsivity of $44 \mathrm{~mA} / \mathrm{W}$ at $263 \mathrm{~nm}$. A true solar-blind cut-off wavelength of $274 \mathrm{~nm}$ and a solar-blind/near-UV contrast of more than three orders of magnitude were demonstrated. Time-domain high-frequency measurements resulted in 3-dB bandwidths as high as 1.10 GHz. The high-speed performance achieved with our solarblind ITO Schottky detectors correspond to the best results reported for solar-blind photodetectors.

This work was supported by NATO Grant No. SfP971970, Turkish Department of Defense Grant No. KOBRA-002, and FUSAM-03.

${ }^{1}$ M. Razeghi and A. Rogalski, J. Appl. Phys. 79, 7433 (1996).

${ }^{2}$ D. Walker, V. Kumar, K. Mi, P. Sandvik, P. Kung, X. H. Zhang, and M. Razeghi, Appl. Phys. Lett. 76, 403 (2000).

${ }^{3}$ M. M. Wong, U. Chowdhury, C. J. Collins, B. Yang, J. C. Denyszyn, K. S. Kim, J. C. Campbell, and R. D. Dupuis, Phys. Status Solidi A 188, 333 (2001).

${ }^{4}$ B. Yang, D. J. H. Lambert, T. Li, C. J. Collins, M. M. Wong, U. Chowdhury, R. D. Dupuis, and J. C. Campbell, Electron. Lett. 36, 1866 (2000).

${ }^{5}$ V. V. Kuryatkov, H. Temkin, J. C. Campbell, and R. D. Dupuis, Appl. Phys. Lett. 78, 3340 (2001)

${ }^{6}$ P. Sandvik, K. Mi, F. Shahedipour, R. McClintock, A. Yasan, P. Kung, and M. Razeghi, J. Cryst. Growth 231, 366 (2001).

${ }^{7}$ A. Hirano, C. Pernot, M. Iwaya, T. Detchprohm, H. Amano, and I. Akasaki, Phys. Status Solidi A 188, 293 (2001).

${ }^{8}$ T. Li, D. J. H. Lambert, A. L. Beck, C. J. Collins, B. Yang, M. M. Wong, U. Chowdhury, R. D. Dupuis, and J. C. Campbell, Electron. Lett. 36, 1581 (2000).

${ }^{9}$ C. J. Collins, U. Chowdhury, M. M. Wong, B. Yang, A. L. Beck, R. D. Dupuis, and J. C. Campbell, Appl. Phys. Lett. 80, 3754 (2002).

${ }^{10}$ C. J. Collins, U. Chowdhury, M. M. Wong, B. Yang, A. L. Beck, R. D. Dupuis, and J. C. Campbell, Electron. Lett. 38, 824 (2002).

${ }^{11}$ J. C. Carrano, T. Li, D. L. Brown, P. A. Grudowski, C. J. Eiting, R. D. Dupuis, and J. C. Campbell, Appl. Phys. Lett. 73, 2405 (1998).

${ }^{12}$ J. C. Carrano, T. Li, D. L. Brown, P. A. Grudowski, C. J. Eiting, R. D. Dupuis, and J. C. Campbell, Electron. Lett. 34, 1779 (1998).

${ }^{13}$ N. Biyikli, T. Kartaloglu, O. Aytur, I. Kimukin, and E. Ozbay, Appl. Phys. Lett. 79, 2838 (2001).

${ }^{14}$ A. Osinsky, S. Gangopadhyay, B. W. Lim, M. Z. Anwar, M. A. Khan, D. V. Kuksenkov, and H. Temkin, Appl. Phys. Lett. 72, 742 (1998).

${ }^{15}$ J. L. Pau, E. Monroy, E. Munoz, F. Calle, M. A. Sanchez-Garcia, and E. Calleja, Electron. Lett. 37, 239 (2001).

${ }^{16}$ T. Li, D. J. H. Lambert, M. M. Wong, C. J. Collins, B. Yang, A. L. Beck, U. Chowdhury, R. D. Dupuis, and J. C. Campbell, IEEE J. Quantum Electron. 37, 538 (2001).

${ }^{17}$ N. Biyikli, O. Aytur, I. Kimukin, T. Tut, and E. Ozbay, Appl. Phys. Lett. 81, 3272 (2002).

${ }^{18}$ N. Biyikli, I. Kimukin, O. Aytur, M. Gokkavas, M. S. Unlu, and E. Ozbay, IEEE Photonics Technol. Lett. 13, 705 (2001).

${ }^{19}$ I. Kimukin, E. Ozbay, N. Biyikli, T. Kartaloglu, O. Aytur, S. M. Unlu, and G. Tuttle, Appl. Phys. Lett. 77, 3890 (2002). 